\title{
Assessment of the Relationship Between Matrix Metalloproteinase-9 Promoter Gene Polymorphism and Chronic Periodontitis
}

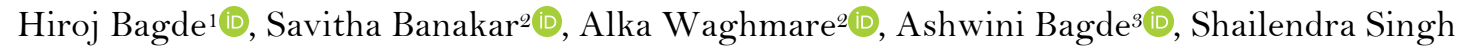

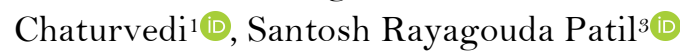

\footnotetext{
'Department of Periodontology, New Horizon Dental College and Research Institute, Bilaspur, India.

'Department of Periodontology, ACPM Dental College, Dhule, India.

${ }^{3}$ Department of Oral Medicine and Radiology, New Horizon Dental College and Research Institute, Bilaspur, India.
}

Correspondence: Santosh Rayagouda Patil, Department of Oral Medicine and Radiology, New Horizon Dental College and Research Institute, Bilaspur, 495001, India. E-mail: drpsantosh@gmail.com

Academic Editor: Yuri Wanderley Cavalcanti

Received: 23 December 2020 / Review: 21 February 2021 / Accepted: 05 April 2021

How to cite: Bagde H, SBanakar S, Waghmare A, Bagde A, Chaturvedi SS, Patil SR. Assessment of the relationship between matrix metalloproteinase-9 promoter gene polymorphism and chronic periodontitis. Pesqui Bras Odontopediatria Clín Integr. 202 1; 21 :e0264. https://doi.org/10.1590/pboci.2021.123

\begin{abstract}
Objective: To evaluate the association of MMP-9 promoter gene polymorphism in generalized chronic periodontitis patients of an Indian population. Material and Methods: Eighty patients were selected and divided into case and control groups $(\mathrm{n}=40)$. Patients included were aged $15-60$ years of both genders and diagnosed with chronic periodontitis. Peripheral venous blood samples were obtained, and genomic DNA was isolated by a 'salting out' method. Three possible genotypes were distinguished by three distinct banding patterns, depending on the presence or absence of the Sph I restriction site: CC as allele 1, TT as allele 2, and CT, respectively. Statistical analysis was carried out by applying the Chi-squared test and Oneway ANOVA. Results: There was a significant difference in MMP-9 genotypes between Chronic periodontitis patients and healthy controls. Odds ratios for CT genotype and combination of CT and TT genotypes were 3.125 (95\% confidence interval, $\mathrm{p}=0.028$ ) and 3.667 (95\% confidence interval, $\mathrm{p}=0.006$ ) relative to subjects with $\mathrm{CC}$ genotype, respectively. Conclusion: The present study revealed an association of MMP-9 (-1562 C/T) gene polymorphism with generalised chronic periodontitis.
\end{abstract}

Keywords: Periodontitis; Genetics; Matrix Metalloproteinase 9. 


\section{Introduction}

Periodontal diseases contribute significantly to the global burden of oral diseases. They are initiated by microbial plaque, which accumulates in the gingival crevice region and induces an inflammatory response. The primary inflammation, i.e., gingivitis, may progress in specific susceptible individuals to the chronic destructive inflammatory condition termed periodontitis. The bone and other tooth-supporting tissues are destroyed, and the changes are irreversible [1-3].

The periodontal disease process appears to be modified by genetic factors, environmental factors, and acquired conditions [4]. While microbial and other environmental factors are believed to initiate disease, there is strong supporting evidence that genes play a role in the predisposition and progression of periodontal diseases [5-7].

Genetic variation, a relatively recent focus in periodontology, has been to quantify genetic risk and identify specific gene variants that determine disease susceptibility [8]. Knowledge of genetic markers could enable clinicians to direct environmentally based prevention and provide new treatment strategies to individuals who are more susceptible to disease [9]. Chronic periodontitis appears to be genetically complex. Therefore, studies have focused on evaluating several genetic variants (polymorphisms) occurring in human genes $[10]$.

Many genetic polymorphisms have been studied for an association with chronic periodontitis, including several interleukin (IL) gene [11,12], the tumor necrosis factor- $\beta$ gene, MMP-9 gene [13] and several human leukocyte antigen (HLA) variants [14]. Matrix metalloproteinases (MMP's) are considered to be primary proteinases involved in periodontal tissue destruction by degradation of extracellular matrix molecules such as collagen, gelatin and elastin [15]. Therefore, an imbalance between MMPs and their host inhibitors could lead to periodontal diseases by initiating structural protein destruction [16,17].

They are also produced by periodontal pathogens like Porphyromonas gingivalis and Actinobacillus actinomycetemcomitans. Studies have substantiated the relationship between MMP's and periodontitis by showing elevated levels of MMP -1, -2, -3, -7, -8, -9 in tissues and gingival crevicular fluid (GCF) of chronic periodontitis patients [18-21]. MMP-9, also known as gelatinase B or 92-kDa type IV collagenase, plays a significant role in the breakdown of type IV collagen as well as the basement membrane through its gelatinase activity [15,17]. Also, MMP 9 promoter gene affects MMP 9 formation and activation of the degradation activity in the collagen breakdown [18]. Investigators predict that information concerning polymorphism will be useful in the prevention and therapy of periodontitis and the early recognition of patients who need more comprehensive therapy [22]. MMP-9 $-1562 \mathrm{C}>\mathrm{T}$ was also found to have a protective effect against chronic periodontitis but had no connection to Aggressive Periodontitis [23].

Hence the present study was carried out to evaluate the association of MMP-9 promoter gene polymorphism in generalized chronic periodontitis patients of an Indian population.

\section{Material and Methods}

Ethical Clearance

The study protocol (No. PG/11/PERIO/1) was approved by the Ethical Committee of the college. The study objectives were explained to the patients and signed consent was obtained from all the participants prior to commencement of the study. 
Without previous data available in the literature, a prevalence of 0.5 was considered. The confidence interval was set at $95 \%$, with precision 1, to the extent that a margin of error of $10 \%$ was acceptable. Given these variables, 80 patients were required. By minimizing the margin of error and increasing the accuracy, the sample number would increase according to the usual parameters.

All the 80 patients were divided into two groups, comprising of 40 patients in each group: Group I (Control): Patients with clinically healthy periodontium as determined by the absence of Clinical Attachment Loss (CAL) and no sites with Probing Depth (PD) >3mm; Group II (Generalised Chronic Periodontitis/Case): Patients exhibiting Clinical Attachment Loss $(\mathrm{CAL})>3 \mathrm{~mm}$, also Probing Depth $>5 \mathrm{~mm}$ in at least 6 sites.

\section{Data Collection}

The patients for this study were selected from the Out-Patient Department of Periodontics in ACPM Dental College, Dhule, Maharashtra, India. It was carried out on systemically healthy patients with healthy periodontium and chronic periodontitis assessed by the clinical parameters.

The following inclusion criteria were established: Patients with an age range of 15-60 years including both genders; Diagnostic criteria for chronic periodontitis [1]: a) Patients with a minimum of 20 permanent teeth in the mouth; b) Patients with normal alignment of teeth; c) At least six sites having probing depth $>5$ $\mathrm{mm}$. In addition, the following exclusion criteria were established: Patients with history or manifestation of systemic disease, especially cardiovascular disorders (hypertension, coronary heart diseases, atherosclerosis), bleeding disorders, hepatitis, obesity, diabetic mellitus and HIV infections; Intake of any drugs known to affect the periodontium in past three months such as Antiepileptic drugs, NSAID's, etc.; Patients with diseases of the oral hard or soft tissues except caries and periodontal disease like red and white lesions, benign or malignant conditions, etc.; Pregnant and lactating mothers and patients with a history of smoking.

Genomic DNA was extracted from the sample of epithelial cells. This DNA was then used for detecting SNP at MMP-9 (-1562 C/T) employing polymerase chain reaction (PCR). The three possible genotypes were distinguished by three distinct banding patterns, depending on the presence or absence of the SphI restriction site: homozygous factors CC (560 bp) as allele 1, TT (360 and 300 bp) as allele 2 , and heterozygous fragment CT $(560,360$, and $300 \mathrm{bp})$ respectively. The following parameters were recorded prior to the commencement of the study: Plaque Index [23], Gingival Index [24], Probing Depth and Clinical Attachment Loss.

Five $\mathrm{ml}$ of blood was collected from the antecubital fossa by venipuncture using 20-gauge needles with $5 \mathrm{ml}$ syringes and immediately transferred to EDTA vial and analyzed for single nucleotide polymorphism analysis matrix metalloproteinase -9 by polymerase chain reaction technique [13]. Peripheral venous blood samples from all subjects were obtained, and genomic DNA was isolated by a "salting out" method from peripheral leukocytes. The alleles of the $\mathrm{C} / \mathrm{T}$ polymorphism at position -1562 in the promoter region of the MMP-9 gene were distinguished by cutting with the SphI restriction enzyme. The polymorphic site was amplified using forward (59-TTC GTG ACG CAA AGC AGA-39) and reverse primers (59-AGC AGC CTC CCT CAC TCC T-39). A 560-base pair (bp) fragments encompassing the SphI polymorphic site were amplified. Polymerase chain reaction (PCR) was performed using a $25 \mathrm{ml}$ solution containing PCR buffer with MMP-9 marker, 20 pmol of each primer, $3.5 \mathrm{mM} \mathrm{MgCl}_{2}, 200 \mathrm{mMdNTP}, 200 \mathrm{ng}$ DNA, and $1.25 \mathrm{U}$ Taq polymerase. After initial denaturation at $95^{\circ} \mathrm{C}$ for 3 minutes, amplification was performed by 35 cycles of denaturation at $95^{\circ} \mathrm{C}$ for 1 minute, annealing at $65^{\circ} \mathrm{C}$ for 45 seconds, and extension at $72^{\circ} \mathrm{C}$ for 45 seconds. Final extension was allowed to proceed at $72^{\circ} \mathrm{C}$ for 5 minutes. PCR products $(15 \mathrm{ml})$ were digested with $10 \mathrm{U}$ 
of Sph I restriction enzyme in $1.9 \mathrm{ul} 10 \mathrm{x}$ buffer, $0.5 \mathrm{ul}$ of $100 \mathrm{x}$ bovine serum albumin, and $5 \mathrm{ml}$ of water at $37^{\circ}$ $\mathrm{C}$ overnight. The digested product was resolved on 3\% agarose and analyzed using a video gel documentation system after staining with ethidium bromide. The three possible genotypes were distinguished by three distinct banding patterns, depending on the presence or absence of the Sph I restriction site: CC (560 bp) as allele 1, TT (360 and $300 \mathrm{bp}$ ) as allele 2 and CT (560, 360, and $300 \mathrm{bp}$ ) respectively. All the recorded values of clinical parameters and genotype distribution of MMP-9 (-1562 C/T) from different study groups were subjected to statistical analysis.

\section{Statistical Analysis}

The obtained data were analyzed by using the Statistical Package for the Social Sciences (SPSS), version 21.0 (IBM Corp., Armonk, NY, USA) and a value of $\mathrm{p}<0.05$ was considered to be statistically significant. Associations between the periodontitis and genotypes were assessed by calculating odds ratio (OR) and $95 \%$ confidence intervals (CIs). The distribution of the genotype in periodontitis was compared to controls using the chi-squared test. One way ANOVA test was applied to know the difference in the mean plaque index, gingival index, probing depth and clinical attachment loss between control and chronic periodontitis group.

\section{Results}

The age range for group I was 25-42 years and the mean age noted was $32.5 \pm 5.1$ years (Table 1). The age range for group II was 26-52 years and the mean age noted was $38.7+8.3$ years. Between groups I and II, the mean difference in age range was $6.10(\mathrm{p}<0.05)$. The gender distribution for group I was 23 males $(58 \%)$ and 17 females (43\%). The gender distribution for group II was 20 males (50\%) and 20 females (50\%). Comparison of gender distribution between the groups was not statistically significant (p>0.05) (Table 2).

Table 1. Age-wise distribution of subjects in the case and control group.

\begin{tabular}{lccc}
\hline \multicolumn{1}{c}{ Age (Years) } & Control & Groups & p-value* \\
& $38.7 \pm 8.3$ & $32.5 \pm 5.1$ & $<0.001$ \\
\hline Mean (SD) & $26-52$ & $25-42$ & $<0.001$ \\
Minimum-Maximum & & &
\end{tabular}

Table 2. Comparison of PD and CAL in the case and control group.

\begin{tabular}{lcccc}
\hline \multirow{2}{*}{ Gender } & Control & Case & Total & \\
& $\mathrm{N}(\%)$ & $\mathrm{N}(\%)$ & $\mathrm{N}(\%)$ & p-value* \\
\hline Female & $17(42.5)$ & $20(50.0)$ & $37(46.3)$ & 0.501 \\
Male & $23(57.5)$ & $20(50.0)$ & $43(53.8)$ & \\
$\quad$ Total & $40(100.0)$ & $40(100.0)$ & $80(100.0)$ & \\
*Pearson Chi-Square test. & & &
\end{tabular}

The mean plaque index score for group I was $0.6 \pm 0.1$, for group II was $1.7 \pm 0.4$. On comparison of plaque index scores between groups I and II, the mean difference was 1.10, which was statistically significant $(\mathrm{p}<0.001)$ (Table 3). The mean gingival index score for group I was $0.22 \pm 0.17$, for group II was $2.03 \pm 0.2$. On comparison of gingival index scores between groups I and II, the mean difference was 1.80, which was statistically significant $(\mathrm{p}<0.001)$ (Table 3). The mean probing depth score for group I was $1.87 \pm 0.80$, for group II was 7.0 \pm 1.5. On comparison of probing depth scores between groups I and II, the mean difference in 
probing depth score was 5.16, which was statistically significant $(\mathrm{p}<0.001)$ (Table 3). The mean clinical attachment loss score for group I was 0.00 and for group II was $7.1 \pm 1$.2. In a comparison of clinical attachment loss scores between groups I and II, the mean difference in clinical attachment loss score was 7.1, which was statistically significant $(\mathrm{p}<0.001)$ (Table 3$)$.

Table 3. Comparison of PD and CAL in the case and control group.

\begin{tabular}{lccc}
\hline \multicolumn{1}{c}{ Clinical Parameters } & Case & Control & p-value* \\
& Mean (SD) & Mean (SD) & \\
\hline Plaque Index & $1.7 \pm 0.4$ & $0.6 \pm 0.1$ & $<0.001$ \\
Gingival Index & $2.03 \pm 0.2$. & $0.22 \pm 0.17$ & $<0.001$ \\
Probing Depth & $7 \pm 1.5$ & $1.87 \pm 0.8$ & $<0.001$ \\
Clinical Attachment Level & $7.11 \pm 0.6$ & 0.0 & $<0.001$ \\
\hline *Pearson Chi-Square test. & & &
\end{tabular}

The CC genotype was observed at a frequency of $30(75 \%)$ and $18(45 \%)$ in groups I and II, respectively. The CT genotype was observed at a frequency of $8(20 \%)$ and $15(38 \%)$ in group I and group II, respectively. The TT genotype was observed at a frequency of $2(5 \%)$ and $7(18 \%)$ in groups I and II, respectively (Table 4). Between groups I and II, the distribution of CC genotype was higher in group I when compared to Group II ( $75 \%$ versus $45 \%$, respectively), the distribution of CT genotype was lower in group I than group II (20\% versus $37 \%$, respectively) and the distribution of TT genotype was lower in group I than group II (5\% versus 17\%, respectively). There were a significant difference in MMP-9 (-1562C/T) genotypes between the chronic periodontitis patients and healthy controls (Table 4).

Table 4. Distribution and comparison of genotype in the case and control group.

\begin{tabular}{|c|c|c|c|c|}
\hline & \multicolumn{2}{|c|}{ Groups } & \multirow[t]{2}{*}{ OR 95\% CI } & \multirow[b]{2}{*}{ p-value } \\
\hline & $\begin{array}{c}\text { Case } \\
\mathrm{N}(\%)\end{array}$ & $\begin{array}{c}\text { Control } \\
\mathrm{N}(\%)\end{array}$ & & \\
\hline \multicolumn{5}{|l|}{ Genotype } \\
\hline $\mathrm{CC}$ & $18(45.0)$ & $30(75.0)$ & 1.0 (Ref.) & \\
\hline $\mathrm{CT}$ & $15(37.5)$ & $8(20.0)$ & 3.125 & 0.028 \\
\hline $\mathrm{TT}$ & $7(17.5)$ & $2(5.0)$ & 5.833 & 0.025 \\
\hline $\mathrm{CT}+\mathrm{TT}$ & $10(25.0)$ & $22(40.0)$ & 3.667 & 0.006 \\
\hline \multicolumn{5}{|l|}{ Alleles } \\
\hline $\mathrm{T}$ & $29(36.2)$ & $12(15.0)$ & 3.222 & 0.001 \\
\hline $\mathrm{C}$ & $51(63.8)$ & $68(85.0)$ & & \\
\hline
\end{tabular}

*Pearson Chi-Square test.

On comparing 'CT' mutation taking 'CC' as a reference in between case and control group gave a statistically significant result for more disease predilection for CT mutation in chronic periodontitis with an OR value of 3.12 .

On comparing 'TT' mutation taking ' $\mathrm{CC}$ ' as a reference in between case and control group gave a statistically significant result for more disease predilection for TT mutation in chronic periodontitis with an OR of 5.8. On comparison between the groups, the distribution of $\mathrm{T}$ allele carriage (CT+TT) was statistically significant for more disease risk as compared to C allele carriage with an OR of 3.67 (Table 4).

The C allele was observed at a frequency of 68 (85\%) and 51 (64\%) in control (Group I) and generalized chronic periodontitis group (Group II), respectively. The $\mathrm{T}$ allele was observed at a frequency of 12 and 29 with a percentage distribution of $15 \%$ and $36 \%$ in group I and group II, respectively. Between groups I and II, the distribution of C allele was higher in group I than group II ( $85 \%$ versus $64 \%$, respectively), 
and $\mathrm{T}$ allele was lower in group I than group II (15\% versus $36 \%$, respectively) with an Odds ratio of $3.22(95 \%$ CI: 1.5-6.92) which was statistically significant $(\mathrm{p}<0.001)$ (Table 4$)$.

\section{Discussion}

As a result of knowledge advancement, it is evident that there is a genetic basis for most diseases, including periodontitis [19]. This realization has fostered the idea that if we can understand the genetic basis of diseases, genetic tests to assess disease risk and to develop etiology-based treatments will soon be a reality. MMPs are a family of zinc-and calcium-dependent enzymes that degrade a wide range of structural and adhesive extracellular proteins. Elevated levels of MMP-9 were found in tissues and in gingival crevicular fluid of periodontitis patients [20-22]. It has been hypothesized that genetic variation affecting the expression and activity of MMP-9 influences the prevalence and severity of periodontal disease, as they are one of the most important groups of enzymes involved in periodontal tissue remodeling [24-26]. The extravasated degranulating PMNs are the major source of MMP9 in chronic periodontitis and aggressive periodontitis as according to Westerlund et al. [27]. Various studies had considered the role of MMP-9 polymorphisms in pathogenesis of periodontal diseases in diverse populations. De Souza et al. [28] reported that MMP-9 ($1562 \mathrm{C} / \mathrm{T}$ ) polymorphism was not associated with chronic periodontitis $(\mathrm{CP})$ in a Brazilian population. But on the contrary, other authors observed MMP-9 gene association with severe generalized periodontitis in the Turkish population [13].

Between groups II and I, the mean age was 38.7 and 32.5, with a mean difference was $6.1(\mathrm{p}<0.001)$, suggesting that group II patients were older compared to group I, indicating the nature of chronicity for the disease to be established. Our findings were contrary to Keles et al. [13], who observed the mean age of $47.1 \pm$ 9.4 and 44.8 \pm 7.8, de Souza et al. [28], who observed the mean age $43.6 \pm 14.4$ and $43.2 \pm 14.0$ and Holla et al. [29] who found the mean age of $43.7 \pm 6.7$ and $45.8 \pm 7.3$ for group II and I respectively, which was statistically not significant $(\mathrm{p}>0.05)$.

Between groups II and I, the gender distribution (male/female) was statistically insignificant (p>0.05) for both the groups suggesting that both groups were comparable. This is in accordance with Keles et al. [13], who found 32/38, 36/34 (p>0.05) and Holla et al. [29], who observed 87/82, 61/74 (p>0.05) for Group II and I, respectively. The effect of gender on MMP-9 genetic polymorphism is not clear. If any obvious diversity is found between genders, it may be due to hormone concentration. Sex hormone can modulate antigen presentation, lymphocyte activation and cytokine production. An effect of estrogen on the expression of MMP9 has been reported with transcriptional downregulation of MMP-9 promoters by estrogen-activated estrogen receptors. Estrogen may also reduce both plasma levels and tissue effects on MMP-9 [29].

Studies to evaluate the association between MMP 9 gene polymorphism and chronic periodontitis in the Indian population are not available in the literature. Hence this study was carried out to evaluate the same. However, the inclusion of a larger sample with established risk factors of periodontitis helps in assessing the strength of the relationship between genotypes and diseased groups for detection of specific genetic markers, which would guide us in providing appropriate treatment to the susceptible individuals [30].

One-way ANOVA test revealed that the control and chronic periodontitis group showed a difference in the mean plaque index, gingival index, probing depth and clinical attachment loss scores $(\mathrm{p}<0.05)$. Scores of the clinical parameters showed a linear increase with the increasing severity of different clinical forms of periodontitis. 
For groups I and II, plaque index scores being 0.6 and 1.7, respectively, had a mean difference of 1.10, which was statistically significant $(\mathrm{p}<0.001)$, indicating that plaque is the initiating factor though environmental, genetic factors do play important roles in causing periodontitis. Among the study groups, the control group had a lesser plaque index score suggesting a good oral hygiene status. The gingival index was utilized in the study for assessing the severity of gingivitis. The mean gingival index scores for groups I and II were 0.22 and 2.03 , respectively, with a mean difference of 1.80 , which was statistically significant $(\mathrm{p}<0.001)$. The mean probing depth scores for groups I and II were $1.87 \mathrm{~mm}$ and $7.0 \mathrm{~mm}$, respectively, with a mean difference of $5.166 \mathrm{~mm}$, which was statistically significant $(\mathrm{p}<0.001)$ which is in accordance to Keles et al. [13], where probing depth of $4.7 \pm 0.69$ and $1.8 \pm 0.18$ was observed for groups II and I respectively suggesting the increased periodontal destruction in group II patients.

The mean clinical attachment loss scores for groups I and II were $0 \mathrm{~mm}$ and $7.1 \mathrm{~mm}$, respectively, with a mean difference of $7.1 \mathrm{~mm}(\mathrm{p}<0.001)$. This is in accordance with Keles et al. [13], who found $5.7 \pm$ $0.87 \mathrm{~mm}$ of CAL in group II patients. In most MMP-9 genetic polymorphism studies, clinical parameters like plaque index, gingival index, probing depth and clinical attachment loss were used to categorize the study groups. However, in the literature, studies wherein the clinical parameters are compared are very limited.

Between groups II and I, CC Genotype distribution was higher in group I than group II ( $75 \%$ vs. $45 \%$, respectively), which is not in accordance with and Keles et al. [13], (60.0\% vs. 81\%), de Souza et al. [28], (63.2\% vs. $71.4 \%)$ and Holla et al. [29], (68\% vs. 72\%, respectively), CT Genotype distribution was higher in group II than group I (37.5 vs. 20\%, respectively) which is in contrary with Keles et al. [13], (18.6\% vs. $34.3 \%$, respectively), de Souza et al. [28] (28.6\% vs. 34.2\%) and Holla et al. [29], (25.4\% vs. 27.4\%, respectively), where genotype distribution was lower in group II than group I.

TT Genotype distribution was higher in group II than group I ( $17.5 \%$ vs. 05\%, respectively), which is contrary with Keles et al. [13], (0.0\% vs. 5.7\%, respectively), de Souza et al. [28] (0.0\% vs. 2.6\%) and Holla et al. [29], (2.4\% vs. 3.7\%, respectively), where genotype distribution was lower in group II than group I.

TT genotype is believed to increase MMP transcription. The distribution of MMP-9 genotypes between groups I and II was statistically significant, which is contrary with de Souza et al. [28] and Holla et al. [29], and was in accordance with Keles et al. [13], where a significant difference in genotype distribution was found. This variation in the result may suggest that the development of periodontitis in an individual depends on the collective presence of some environmental risk factors in conjunction with several genetic risk factors at a given point of time.

The study's limitations are that the inclusion of a larger sample with established risk factors of periodontitis helps assess the strength of the relationship between genotypes and diseased groups. In addition, only one gene to be responsible for the disease is not possible; hence multiple genome study for diagnosing the association is a must. Finally, the study design clarifies association but correlation with different ethnic groups has to be carried out to measure disease prevalence.

\section{Conclusion}

This study revealed an association of MMP-9 (-1562 C/T) gene polymorphism with generalised chronic periodontitis. Furthermore, an association of higher $\mathrm{T}$ allele distribution with increased susceptibility and higher $\mathrm{C}$ allele distribution with decreased susceptibility to generalized chronic periodontitis was observed. The genotyping from study groups confirmed the association of MMP-9 (1562 C/T) polymorphism with chronic periodontitis. Furthermore, the association of higher $\mathrm{T}$ allele distribution with increased susceptibility 
and higher $\mathrm{C}$ allele distribution with decreased susceptibility to generalized chronic periodontitis was observed in Indian population within the same ethnicity. Thus, MMP-9 functional promoter gene polymorphism could act as one of the genetic factors that may participate in the complex process of tissue remodeling in patients with generalised chronic periodontitis.

\section{Authors' Contributions}

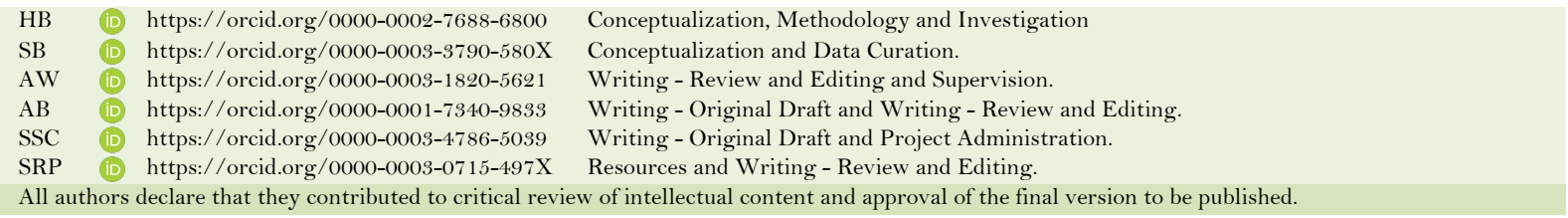

\section{Financial Support}

None.

\section{Conflict of Interest}

The authors declare no conflicts of interest.

\section{Data Availability}

The data used to support the findings of this study can be made available upon request to the corresponding author

\section{References}

[1] Könönen E, Gursoy M, Gursoy UK. Periodontitis: a multifaceted disease of tooth-supporting tissues. J Clin Med 2019; 8(8):1135. https://doi.org/10.3390/jcm8081135

[2] Murakami S, Mealey BL, Mariotti A, Chapple ILC. Dental plaque-induced gingival conditions. J Periodontol 2018; 89(Suppl1):S17-S27. https://doi.org/10.1002/JPER.17-0095

[3] Helmi MF, Huang H, Goodson JM, Hasturk H, Tavares M, Natto ZS. Prevalence of periodontitis and alveolar bone loss in a patient population at Harvard School of Dental Medicine. BMC Oral Health 2019; 19(1):254. https://doi.org/10.1186/s12903-019-0925-z

[4] Loos BG, John RP, Laine ML. Identification of genetic risk factors for periodontitis and possible mechanisms of action. J Clin Periodontol 2005; 32(Suppl 6):159-79. https://doi.org/10.1111/j.1600-051X.2005.00806.x

[5] Mashhadiabbas F, Neamatzadeh H, Foroughi E, Dastgheib SA, Farahnak S, Nasiri R, et al. Association of MMP-2$753 \mathrm{C}>\mathrm{T}$ and MMP-9-1562C $>\mathrm{T}$ polymorphisms with chronic/aggressive periodontitis risk: a systematic review and meta-analysis. Iran J Public Health 2019; 48(7):1227-38.

[6] Aloka D, Padmakumar SK, Sathyan S, Sebastian M, Banerjee M, Beena VT. Association of matrix metalloproteinase 2 and matrix metalloproteinase 9 gene polymorphism in aggressive and nonaggressive odontogenic lesions: A pilot study. J Oral Maxillofac Pathol 2019; 23(1):158. https://doi.org/10.4103/jomfp.JOMFP_2_17

[7] Alotaibi DH, Altalhi AM, Sambawa ZM, Koppolu P, Alsinaidi AA, Krishnan P. The association of matrix metalloproteinase gene polymorphisms and periodontitis: an overview. J Pharm Bioallied Sci 2020; 12(Suppl 1):S37S42. https://doi.org/10.4103/jpbs.JPBS_136_20

[8] Michalowicz BS. Genetic and heritable risk factors in periodontal disease. J Periodontol 1994; 65(5 Suppl):479-88. https://doi.org/10.1902/jop.1994.65.5s.479

[9] Hassell TM, Harris EL. Genetic influences in caries and periodontal diseases. Crit Rev Oral Biol Med 1995; 6(4):31942. https://doi.org/10.1177/10454411950060040401

[10] Hodge P, Michalowicz B. Genetic predisposition to periodontitis in children and young adults. Periodontol 2000 2001; 26:113-34. https://doi.org/10.1034/j.1600-0757.2001.2260106.x

[11] Kornman KS, Crane A, Wang HY, di Giovine FS, Newman MG, Pirk FW, et al. The interleukin-1 genotype as a severity factor in adult periodontal disease. J Clin Periodontol 1997; 24(1):72-7. https://doi.org/10.1111/j.1600-051x.1997.tbo1187.x

[12] Malo D, Skamene E. Genetic control of host resistance to infection. Trends Genet 1994; 10(10):365-71. https://doi.org/10.1016/0168-9525(94)90133-3

[13] Keles GC, Gunes S, Sumer AP, Sumer M, Kara N, Bagci H, et al. Association of matrix metalloproteinase-9 promoter gene polymorphism with chronic periodontitis. J Periodontol 2006; 77(9):1510-4. https://doi.org/10.1902/jop.2006.050378 
[14] Dyer JK, Peck MA, Reinhardt RA, Duckworth WC, Booth SJ, Seymour GJ, et al. HLA-D types and serum IgG responses to Capnocytophaga in diabetes and periodontitis. J Dent Res 1997; 76(12):1825-32. https://doi.org/10.1177/00220345970760120401

[15] Ryan ME, Golub LM. Modulation of matrix metalloproteinase activities in periodontitis as a treatment strategy. Periodontol 2000 2000; 24:226-38. https://doi.org/10.1034/j.1600-0757.2000.2240111.x

[16] Souza JA, Rossa C Jr, Garlet GP, Nogueira AV, Cirelli JA. Modulation of host cell signaling pathways as a therapeutic approach in periodontal disease. J Appl Oral Sci 2012; 20(2):128-38. https://doi.org/10.1590/s1678-77572012000200002

[17] Uitto VJ, Overall CM, McCulloch C. Proteolytic host cell enzymes in gingival crevice fluid. Periodontol 2000 2003; 31:77-104. https://doi.org/10.1034/j.1600-0757.2003.03106.x

[18] Pozo P, Valenzuela MA, Melej C, Zaldívar M, Puente J, Martínez B, et al. Longitudinal analysis of metalloproteinases, tissue inhibitors of metalloproteinases and clinical parameters in gingival crevicular fluid from periodontitis-affected patients. J Periodontal Res 2005; 40(3):199-207. https://doi.org/10.1111/j.1600-0765.2005.00786.x

[19] Birkedal-Hansen H. Role of matrix metalloproteinases in human periodontal diseases. J Periodontol 1993; 64(5 Suppl):474-84. https://doi.org/10.1902/jop.1993.64.5s.474

[20] Ingman T, Tervahartiala T, Ding Y, Tschesche H, Haerian A, Kinane DF, et al. Matrix metalloproteinases and their inhibitors in gingival crevicular fluid and saliva of periodontitis patients. J Clin Periodontol 1996; 23(12):1127-32. https://doi.org/10.1111/j.1600-051x.1996.tbo1814.x

[21] Tervahartiala T, Pirila E, Ceponis A, Maisi P, Salo T, Tuter G, et al. The in vivo expression of the collagenolyticmatrix metalloproteinases (MMP-2, -8, -13, and -14) and matrilysin (MMP-7) in adult and localized juvenile periodontitis. J Dent Res 2000; 79(12):1969-77. https://doi.org/10.1177/00220345000790120801

[22] Ejeil AL, Igondjo-Tchen S, Ghomrasseni S, Pellat B, Godeau G, Gogly B. Expression of matrix metalloproteinases (MMPs) and tissue inhibitors of metalloproteinases (TIMPs) in healthy and diseased human gingiva. J Periodontol 2003; 74(2):188-95. https://doi.org/10.1902/jop.2003.74.2.188

[23] Pan Y, Li D, Cai Q, Zhang W, Ma J, Wang M, et al. MMP-9 -1562C > T contributes to periodontitis susceptibility. J Clin Periodontol 2013; 40:125-30.

[24] Löe H. The Gingival Index, the Plaque Index and the Retention Index Systems. J Periodontol 1967; 38(6):Suppl:6106. https://doi.org/10.1902/jop.1967.38.6.610

[25] Theilade E, Wright WH, Jensen SB, Löe H. Experimental gingivitis in man. II. A longitudinal clinical and bacteriological investigation. J Periodontal Res 1966; 1:1-13. https://doi.org/10.1111/j.1600-0765.1966.tb01842.x

[26] Kinane DF, Hart TC. Genes and gene polymorphisms associated with periodontal disease. Crit Rev Oral Biol Med 2003; 14(6):430-49. https://doi.org/10.1177/154411130301400605

[27] Westerlund U, Ingman T, Lukinmaa PL, Salo T, Kjeldsen L, Borregaard N, et al. Human neutrophil gelatinase and associated lipocalin in adult and localized juvenile periodontitis. J Dent Res 1996; 75(8):1553-63. https://doi.org/10.1177/00220345960750080601

[28] de Souza AP, Trevilatto PC, Scarel-Caminaga RM, de Brito RB Jr, Barros SP, Line SR. Analysis of the MMP-9 (C$1562 \mathrm{~T}$ ) and TIMP-2 (G-418C) gene promoter polymorphisms in patients with chronic periodontitis. J Clin Periodontol 2005; 32(2):207-11. https://doi.org/10.1111/j.1600-051X.2005.00665.x

[29] Holla LI, Fassmann A, Muzík J, Vanek J, Vasku A. Functional polymorphisms in the matrix metalloproteinase-9 gene in relation to severity of chronic periodontitis. J Periodontol 2006; 77(11):1850-5. https://doi.org/10.1902/jop.2006.050347

[30] Gürkan A, Emingil G, Saygan BH, Atilla G, Çınarcık S, Köse T, et al. Matrix metalloproteinase-2, -9, and -12 gene polymorphisms in generalized aggressive periodontitis. J Periodontol 2007; 78(12):2338-47. https://doi.org/10.1902/jop.2007.070148 